\title{
The Efficacy and Safety of Paravertebral Block Combined with Parecoxib During Video-Assisted Thoracic Surgery: A Randomized Controlled Trial
}

This article was published in the following Dove Press journal:

Journal of Pain Research

\author{
Junling Yang' \\ Zaijun $\mathrm{Hao}{ }^{\prime}$ \\ Wei $\mathrm{Li}^{\mathrm{I}}$ \\ Caiping Duan' \\ Xiujuan Fan' \\ Jing Xin' \\ Chunguang Ren (iD) ${ }^{2}$ \\ 'Department of Anesthesiology, Ordos \\ Central Hospital, Ordos, People's \\ Republic of China; ${ }^{2}$ Department of \\ Anesthesiology, Liaocheng People's \\ Hospital, Liaocheng, Shandong, People's \\ Republic of China
}

\begin{abstract}
Background: Although video-assisted thoracoscopic surgery (VATS) is increasingly used, the optimal analgesia strategy is still unknown. We explore the efficacy and safety of preemptive ultrasound-guided paravertebral block (PVB) combined with parecoxib during VATS.

Methods: Seventy-four patients were divided into two groups. PVBs were performed before anesthesia induction under real-time ultrasound guidance. Visual analog scale (VAS) score with coughing at $48 \mathrm{~h}$ after surgery, postoperative sufentanil consumption and level of sedation (LOS) at 1, 4, 8, 12, 24, and $48 \mathrm{~h}$ postoperatively, intraoperative hemodynamics, satisfaction scores of patients and surgeons, remedial measures, time to chest tube removed and mobilization, adverse effects and hospital stay length were recorded. We also recorded inflammatory markers, respiratory function and the prevalence of chronic pain after surgery. Results: VAS scores at rest and with coughing during the first $24 \mathrm{~h}$ after surgery were significantly lower in the $\mathrm{P}$ group $(P<0.05)$. Consumption of sevoflurane, remifentanil, and dexmedetomidine was all significantly reduced in the $\mathrm{P}$ group $(P<0.05)$. The consumption of sufentanil within $48 \mathrm{~h}$ after surgery, time to first dose and total dose of rescue ketorolac was significantly lower in the $\mathrm{P}$ group $(P<0.05)$. The FEV1/FVC ratio was significantly higher in the $\mathrm{P}$ group at 1 and $3 \mathrm{~d}$ after surgery $(P<0.05)$. Times to chest tube removal and mobilization were significantly shorter in the $\mathrm{P}$ group $(P<0.05)$. Compared with the $\mathrm{C}$ group, the level of both ACTH and cortisol was significantly reduced in the $\mathrm{P}$ group at 1 and $3 \mathrm{~d}$ after surgery $(P<0.05)$. Conclusion: PVB combined with parecoxib was associated with better pain relief, decreased sufentanil and ketorolac consumption, less hemodynamic instability, and a lower surgery-related stress response. However, the incidences of chronic pain 3 and 6 months after surgery and the risk of complication except urinary retention were not significantly different between groups.
\end{abstract}

Keywords: paravertebral block, parecoxib, video-assisted thoracic surgery, preemptive analgesia

\section{Introduction}

Video-assisted thoracic surgery (VATS) is an alternative method in treating pulmonary disease that shortens recovery time and reduces postoperative morbidity. ${ }^{1}$ Although minimally invasive, postoperative pain arising from intercostal muscles, fascia, and even rib and/or nerve injury following VATS remains an issue, especially in the early postoperative period. ${ }^{2}$ Effective postoperative analgesia could reduce morbidity, accelerate patient recovery, and reduce hospital stay and costs. ${ }^{3}$ Traditional patient-controlled 
intravenous analgesia (PCIA) using systemic opioids may be used after VATS, but the analgesic effect can be limited. As a result, less invasive multimodal analgesia strategies are being investigated. The aim of these strategies is to achieve an opioid-sparing effect, enhance postoperative recovery, and shorten hospital stay. ${ }^{4,5}$ The basis of preemptive analgesia is that the nociceptive system will perceive less pain if analgesia is given before the injury, and has been verified in both animal and human volunteer studies. ${ }^{6,7}$

A systematic review highlighted the superiority of regional techniques for analgesia during thoracotomy. Thoracic epidural block (TEB), paravertebral block (PVB), intercostal nerve block (ICB), and surgical wound infiltration are commonly used techniques. ${ }^{8}$ TEB has been considered the gold standard for pain control after thoracotomy, but it is contraindicated in patients taking anticoagulants or with abnormal anatomical structure. Because there are differences between thoracotomy and VATS, it has been debated whether TEB should also be considered the gold standard in VATS. Due to the shorter postoperative pain duration after VATS, many studies concluded the risks of TEB may outweigh its benefits. $^{9,10}$ Although multiple meta-analyses showed that PVB can provide comparable pain relief to TEB, data from a nationwide French questionnaire study in 2015 suggested that TEB or PVB were the preferred strategy to provide analgesia for VATS, even when communicating with surgical and managerial teams. ${ }^{11,12}$ The results of previous studies did not clearly establish noninferiority of ICB to PVB. As a result, ICB is only employed when TEB or PVB cannot be adopted. ${ }^{8}$ Regional techniques combined with general anesthesia have been adopted to provide better postoperative analgesia and decrease the surgical stress response, which is particularly important for tumor patients with impaired immune function. $^{13-15}$

Because it mitigates pain hypersensitivity and has an opioid-sparing effect, the cyclooxygenase-2 (COX-2)selective inhibitor parecoxib has been increasingly used as a perioperative multimodal analgesic regimen. ${ }^{16,17}$ The aim of this randomized, controlled trial was to investigate the analgesic efficacy and safety of PVB combined with parecoxib and to assess postoperative outcomes in patients undergoing VATS.

\section{Methods}

\section{Patients}

This pilot study was designed according to the CONSORT 2010 statement. We obtained ethical approval from the
Institutional Review Boards of both Liaocheng People's Hospital and Ordos Central Hospital to conduct this prospective, randomized, controlled trial. Written informed consent was obtained from patients or their guardian before participation in this trial. The trial was also registered at chictr.org (ChiCTR-TRC-14004191).

Patients who underwent VATS under general anesthesia in our hospital between November 2017 and November 2018 were recruited. Patients were enrolled in this study if they met the following inclusion criteria: age between 45 and 65 years, American Society of Anesthesiologists (ASA) physical classification I to II, intubated with an L-double-lumen bronchial tube, and received 48-h PCIA after surgery. Exclusion criteria were contraindications to PVB (empyema, neoplastic mass occupying paravertebral space, infection at injection site, coagulative abnormality, severe spine or chest wall deformity), body mass index (BMI) $>30 \mathrm{~kg} / \mathrm{m}^{2}$, abnormal liver or renal function (aspartate aminotransferase or alanine aminotransferase $>40 \mathrm{U} / \mathrm{L}$, creatinine level $>1.5 \mathrm{mg} / \mathrm{dL}$ ), history of cerebrovascular disease, preoperative forced expiratory volume in $1 \mathrm{~s}$ (FEV1) $<60 \%$, active peptic ulcer or peptic bleeding, chronic pain, central nervous system diseases, allergy to local anesthetics or non-steroidal anti-inflammatory drugs, or unable to comprehend or follow verbal and physical instructions.

\section{Randomization and Blinding}

Patients were randomly allocated by a computer-generated random number list to the $\mathrm{P}$ or $\mathrm{C}$ group upon entering the operating room. Patients, anesthesiologists, surgeons, and nurses were all unaware of the group assignment. In the $\mathrm{P}$ group, $40 \mathrm{mg}$ parecoxib was given intravenously $30 \mathrm{~min}$ before surgery and then every $12 \mathrm{~h}$ postoperatively for $48 \mathrm{~h}$. In the $\mathrm{C}$ group, normal saline was given to the patients at the same intervals. Nurses in the acute pain service team educated patients how to evaluate their pain using a visual analog scale (VAS) of 0 to $10(0=$ no pain, $10=$ worst pain $)$, prepared the study drugs and PCIA pump, and performed postoperative assessments such as pain evaluation and side effects.

\section{Anesthesia}

The regimen was similar to that we described previously. ${ }^{18}$ In brief, after arriving at the operating room, all patients were under standard ASA monitoring including electrocardiography, pulse oximetry, noninvasive blood pressure, end-tidal $\mathrm{CO}_{2}$, and temperature. Next, an arterial cannula 
was placed in the left radial artery, and the electrodes of the bispectral index (BIS) were placed on the side of the patient's forehead according to the manufacturer's instructions (Aspect Medical System, Newton, MA). After applying nasal cannula oxygen at $2 \mathrm{~L} / \mathrm{min}$, intravenous sedation was administered with $0.02 \mathrm{mg} / \mathrm{kg}$ midazolam and $1 \mu \mathrm{g} / \mathrm{kg}$ fentanyl. Anesthesiologists performed the PVB. Anesthesia was induced by intravenous administration of propofol $(1.5-2 \mathrm{mg} / \mathrm{kg})$, fentanyl $(2-3 \mu \mathrm{g} / \mathrm{kg})$, and cisatracurium $(0.2 \mathrm{mg} / \mathrm{kg})$. Anesthesia was maintained with sevoflurane $(2-3 \%)$ and dexmedetomidine $(0.2-0.7$ $\mu \mathrm{g} / \mathrm{kg} / \mathrm{h}$ ) titrated according to the BIS (maintained between 50 and 60) and hemodynamics. Supplemental dosing of $0.04 \mathrm{mg} / \mathrm{kg}$ of cisatracurium was given every hour from induction up to approximately $1 \mathrm{~h}$ prior to the end of surgery.

\section{Surgical Procedure}

The position of the tube was verified with fiberoptic bronchoscopy before the patient was turned to a lateral decubitus position, and the upper arm was raised on an arm rest with 90-degree anterior flexion and 60-degree flexion of the elbow to avoid distraction of the ipsilateral shoulder joint according to a previous study. ${ }^{19}$ Surgeons used the same standardized technique with three ports during VATS.$^{20}$ After the ipsilateral lung totally collapsed, the largest incision was performed about $5 \mathrm{~cm}$ from the anterior axillary line at the 4th intercostal space. The other two incisions were $\sim 1 \mathrm{~cm}$ and used for inserting the thoracoscopic video-probe at the 7th intercostal space and surgical instruments at the 8th intercostal space. The chest tube was placed in the 7th or 8th intercostal space at the end of surgery. All patients were transferred to the postanesthesia care unit (PACU) and participated in a rigorous postoperative physiotherapy program. Afterward, patients were transferred to the intensive care unit of the thoracic department for the next $48 \mathrm{~h}$.

\section{Paravertebral Block Procedure}

All blocks were performed before anesthesia induction under real-time ultrasound guidance utilizing the SonoSite M-Turbo ultrasound machine and a linear 4-10 $\mathrm{MHz}$ ultrasound probe (FUJIFILM SonoSite, Bothell, WA) after placing the patient in the lateral decubitus position according to a previous study. ${ }^{21}$ Briefly, the probe was placed at the level of T4-8 and moved laterally (about $2-2.5 \mathrm{~cm}$ from the midline) until visualization of two adjacent transverse processes and the hyperechoic pleural border. Then, a 22-gauge Tuohy needle was inserted in a lateral-to-medial direction until the needle tip penetrated the internal intercostal membrane. Intermittent injection with $0.5 \mathrm{~mL}$ normal saline was applied to assist locating the needle tip. After a negative aspiration, the anesthetic drug was slowly injected into the paravertebral space from $\mathrm{T} 4$ to T8 (patients in $\mathrm{P}$ group with $5 \mathrm{~mL}$ of $0.5 \%$ ropivacaine containing $0.3 \mu \mathrm{g} / \mathrm{kg}$ dexmedetomidine in each space, while patients in $\mathrm{C}$ group received the same volume of $0.5 \%$ ropivacaine). Downward displacement of the pleura indicated proper spread of the local anesthetic. Visceroparietal pleural interface M-mode ultrasound was used to confirm visceroparietal pleural interface integrity after block completion. Patients' sensory levels were tested 10-15 min after the procedure using the pinprick method. ${ }^{22}$ Those with sensory block from T3 to T9 were included in the study. A lipid emulsion was available at any time to treat patients with suspected local anesthetic intoxication.

\section{Postoperative Pain Management}

After arriving at the PACU, PCIA was started with $0.8 \mu \mathrm{g} /$ $\mathrm{mL}$ sufentanil. The bolus volume was $2 \mathrm{~mL}$, locked time was $5 \mathrm{~min}$, and 4-h limit was $40 \mathrm{~mL}$. Patients' pain was assessed with the VAS after arrival at the PACU. If the VAS score was $>3$ after bolus analgesics, $15 \mathrm{mg}$ ketorolac was given intravenously. The chest tube was removed if there was no leakage and pleural effusion was $<100 \mathrm{~mL}$ daily. ${ }^{23}$

\section{Data Collection}

The primary endpoint was VAS with coughing at 48 $\mathrm{h}$ after surgery. Pain scores both at rest and with coughing were measured at $1,4,8,12,24$, and $48 \mathrm{~h}$ postoperatively. Secondary outcomes include postoperative sufentanil consumption and level of sedation (LOS, 6-point scale: $0=$ alert; $1=$ mildly drowsy; $2=$ moderately drowsy, easily arousable; $3=$ very drowsy, arousable; $4=$ difficult to arouse; and $5=$ =unarousable) at $1,4,8,12,24$, and 48 h postoperatively; satisfaction scores of patients and surgeons (5-point scale: $1=$ dissatisfied, $5=$ satisfied) at 48 $\mathrm{h}$ postoperatively; cumulative ketorolac dose; time to the first ketorolac supplement; time to chest tube removal and mobilization; adverse effects relating to both PVB and parecoxib; and hospital stay. The concentrations of cortisol, adrenocorticotropic hormone (ACTH) and interleukin6 (IL-6) and the FEV1/forced vital capacity (FVC) ratio were recorded the day before surgery as well as 1 and 3 
$\mathrm{d}$ postoperatively. We also recorded the prevalence of chronic pain 3 and 6 months after surgery via telephone.

Heart rate (HR) and mean arterial pressure (MAP) were recorded at the following time points: arrival at the operating room (T0), before intubation (T1), after intubation (T2); before incision (T3), 30 min after one-lung ventilation (T4), $60 \mathrm{~min}$ after one-lung ventilation (T5), and extubation (T6). Hypotension was defined as systolic arterial pressure (SAP) $<90 \mathrm{mmHg}$ and/or decreased by $>20 \%$ compared with baseline, which was treated with intravenous boluses of $40 \mu \mathrm{g}$ phenylephrine or $6 \mathrm{mg}$ ephedrine. Bradycardia was defined as $\mathrm{HR}<60$ beats per min and/or decrease $>20 \%$ compared with baseline and was treated with intravenous atropine $0.5 \mathrm{mg}$. Hypoxemia was defined as oxygen saturation $<90 \%$ in room air and was treated with oxygen therapy at 2 $\mathrm{L} / \mathrm{min}$. Postoperative urinary retention was defined as no spontaneous micturition for $8 \mathrm{~h}$ or ultrasound-assessed volume of the urinary bladder $>500 \mathrm{~mL} .{ }^{10}$ Hospital discharge criteria included oral intake, pain controlled by oral analgesics, chest tube removed, and absence of pneumothorax. ${ }^{24}$

\section{Statistical Analysis}

The sample size was calculated based on our previous pilot study, in which the average VAS pain score with coughing at $48 \mathrm{~h}$ after surgery was 4.2 in the control group with an approximate standard deviation of 0.8 . Assuming a 1.0-point decrease in pain score was clinically significant, 32 patients were required in each group with $\alpha=0.05$ and $\beta=0.8$. Considering the dropout rate of $15 \%$, we finally recruited 37 patients for each group.

Statistical analyses were conducted using SPSS (Version 22.0, IBM Corp., Armonk, NY). Data are presented as mean \pm standard deviation, median (interquartile range), or number of patients. The normality of data distribution was assessed with the Kolmogorov-Smirnov test. For normally distributed data, groups were compared by analysis of variance (ANOVA) with the Bonferroni correction. For nonnormally distributed data, groups were compared with the Mann-Whitney $U$-test, Pearson chi-square test, or Fisher's exact test as appropriate. Differences were considered significant at $P<0.05$.

\section{Results}

\section{Baseline Characteristics}

The CONSORT diagram was used during patient enrollment (Figure 1). 200 patients who underwent VATS under general anesthesia between November 2017 and November 2018 were recruited. We excluded 126 patients: 28 patients over 65 years old, 6 patients younger than 45 years old, 8 with ASA $>$ II; 18 with contraindications for PVB, 8 patients with BMI $>30 \mathrm{~kg} / \mathrm{m}^{2}, 12$ with abnormal liver or renal function, 13 with a history of cerebrovascular disease, 6 patients with FEV1 $<60 \%$, 9 with active peptic ulcer or peptic bleeding, 16 with chronic pain and central nervous system diseases, and 2 patients who were unable to comprehend or follow verbal and physical instructions. Seventy-four patients were included and divided into two groups: the P group and the $\mathrm{C}$ group. In the primary analysis, a further 5 were excluded because the sensory block did not reach the required level (3 patients from the $\mathrm{P}$ group, and 2 patients from the $\mathrm{C}$ group), giving 34 patients for the $\mathrm{P}$ group, and 35 patients for the $\mathrm{C}$ group. There were no significant differences with the respect to age, body weight, BMI, ASA grade, sex, type of surgery, preoperative concurrent chemoradiation therapy, comorbidities, or pulmonary function between the two groups $(P>0.05$, Table 1$)$.

\section{Intraoperative Variables}

MAP and HR were not significantly different between the two groups from T1 to T6 ( $P>0.05$, Figure 2). Compared with the $\mathrm{C}$ group, consumption of sevoflurane, remifentanil, and dexmedetomidine were significantly reduced in the $\mathrm{P}$ group $(P<0.05$, Table 1$)$. There were no significant differences between the two groups with respect to surgery and anesthesia durations or cisatracurium consumption $(P>0.05$, Table 1). The number of patients using vasoactive agents was significantly reduced in the $\mathrm{P}$ group during surgery $(P<0.05$, Table 1). Additionally, the recovery time was significantly shorter in the $\mathrm{P}$ group $(P<0.01$, Table 4$)$.

\section{Postoperative Variables}

Compared with the $\mathrm{C}$ group, VAS scores both at rest and with coughing during the first $24 \mathrm{~h}$ after surgery were significantly lower in the $\mathrm{P}$ group $(P<0.05$, Figure 3$)$. Sufentanil consumption during the first $48 \mathrm{~h}$ after surgery was significantly lower in the $\mathrm{P}$ group $(P<0.05$, Figure 4$)$.

Although the number of patients who required rescue ketorolac was similar between the two groups $(P=0.171$, Table 2), the time to first dose of rescue ketorolac was significantly longer in $\mathrm{P}$ group ( $P=0.034$, Table 2 ). Additionally, the total dose of rescue ketorolac in the $\mathrm{C}$ group was significantly higher than that of the $\mathrm{P}$ group $(P<0.01$, Table 2$)$. There were no significant differences between the two groups with respect to the level of sedation or satisfaction scores of patients and surgeons ( $P>0.05$, Tables 3 and 4). 


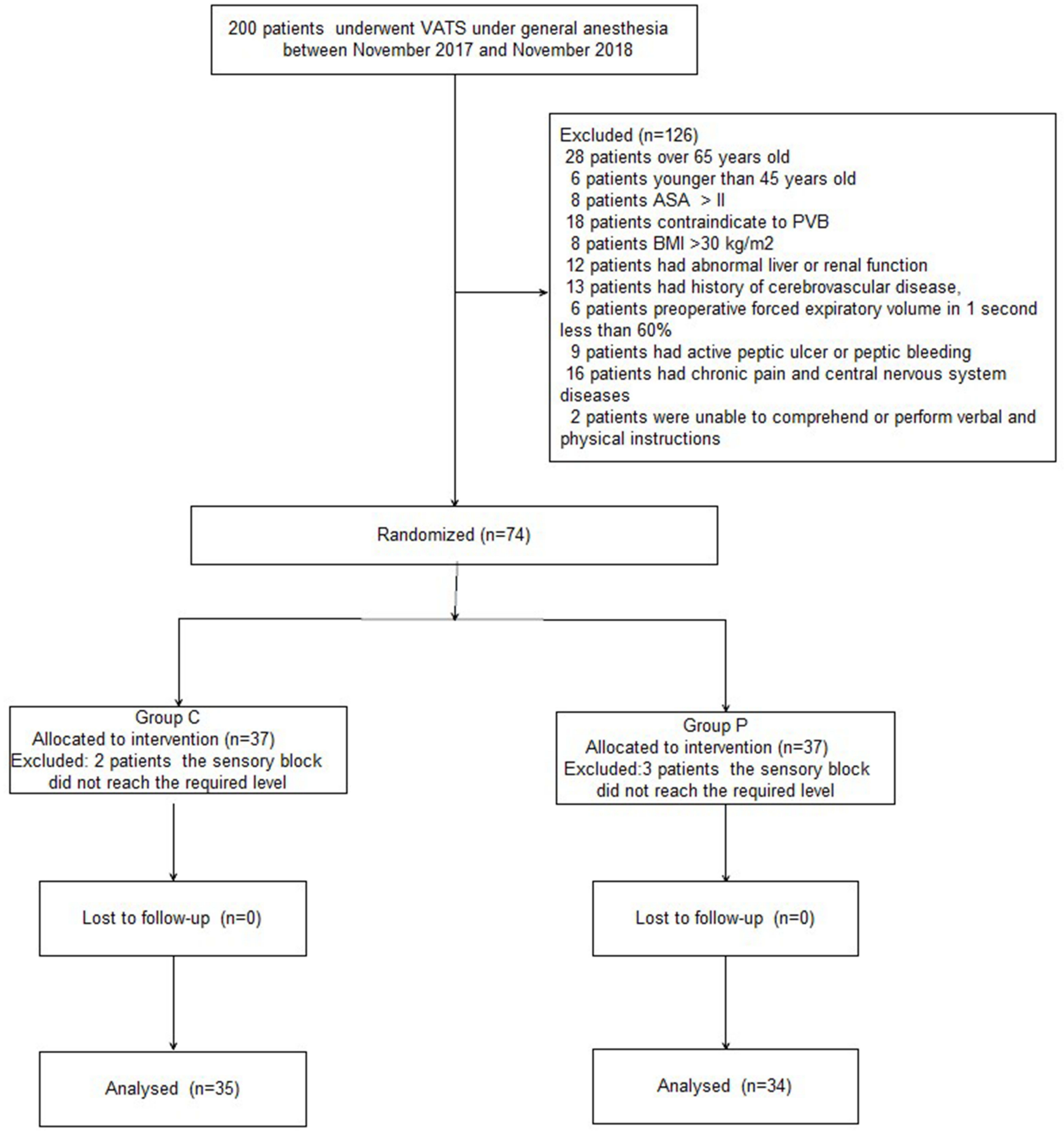

Figure I Patient enrollment flow diagram.

Compared with the $\mathrm{C}$ group, the FEV1/FVC ratio was significantly higher in the $\mathrm{P}$ group at 1 and $3 \mathrm{~d}$ after surgery $(P<0.05$, Table 5$)$. The time to chest tube removal and mobilization were significantly shorter in the P group, although there was no significant difference with respect to the length of stay $(P>0.05$, Table 5$)$.

There were no baseline differences in ACTH, cortisol, or IL-6 concentrations between the two groups $(P>0.05$,
Figure 5). Compared with the $\mathrm{C}$ group, levels of both ACTH and cortisol were significantly reduced in group $\mathrm{P}$ at 1 and $3 \mathrm{~d}$ after surgery $(P<0.05$, Figure $5 \mathrm{~A}$ and $\mathrm{B})$. There was no difference in IL- 6 between groups $3 \mathrm{~d}$ after surgery $(P>0.05$, Figure $5 C)$.

The most common postoperative complication was nausea (54.29\% vs $35.29 \%, P=0.113$, Table 6 ). The incidence of postoperative urinary retention was lower in the $\mathrm{P}$ group 
Table I Patient Demographics and Intraoperative Data

\begin{tabular}{|c|c|c|c|}
\hline & $\begin{array}{l}\text { Group C } \\
(n=35)\end{array}$ & $\begin{array}{l}\text { Group P } \\
(n=34)\end{array}$ & $P$-values \\
\hline Age (years) & $56.77 \pm 4.35$ & $54.91 \pm 3.69$ & 0.055 \\
\hline Sex (female/male, n) & $15 / 20$ & $12 / 22$ & 0.624 \\
\hline Body weight $(\mathrm{kg})$ & $74.27 \pm 8.23$ & $78.04 \pm 9.51$ & 0.083 \\
\hline BMI $\left(\mathrm{kg} \cdot \mathrm{m}^{-2}\right)$ & $25.04 \pm 2.39$ & $25.25 \pm 2.98$ & 0.747 \\
\hline ASA I to II (n) & $7 / 28$ & $10 / 24$ & 0.413 \\
\hline FEVI/FVC (\%) & $89.67 \pm 3.28$ & $90.39 \pm 3.11$ & 0.353 \\
\hline Comorbidity, n (\%) & & & 0.785 \\
\hline Hypertension & $15(42.86 \%)$ & $14(41.18 \%)$ & \\
\hline Diabetes mellitus & 5 (14.29\%) & $8(23.53 \%)$ & \\
\hline Coronary heart disease & 7 (20.00\%) & 9 (26.47\%) & \\
\hline COPD/asthma & $2(5.7 \mid \%)$ & I (2.94\%) & \\
\hline Type of surgery, n (\%) & & & 1.000 \\
\hline Lobectomy & 25 (7I.43\%) & 24 (70.59\%) & \\
\hline Segmentectomy & $6(17.14 \%)$ & 7 (20.59\%) & \\
\hline Wedge resection & 4 (II.43\%) & $3(8.82 \%)$ & \\
\hline Preoperative CCRT, n (\%) & $8(22.86 \%)$ & $6(17.65 \%)$ & 0.766 \\
\hline \multirow[t]{2}{*}{ Duration of surgery (min) } & 128.78 & 119.70 & 0.142 \\
\hline & \pm 12.49 & \pm 10.82 & \\
\hline \multirow[t]{2}{*}{ Duration of anaesthesia $(\mathrm{min})$} & 147.49 & 138.30 & 0.060 \\
\hline & \pm 18.19 & \pm 21.54 & \\
\hline Intraoperative bleeding $(\mathrm{mL})$ & $87.53 \pm 23.87$ & $95.03 \pm 21.82$ & 0.173 \\
\hline \multirow[t]{2}{*}{ Fluids $(\mathrm{mL})$} & 1463.25 & 1395.00 & 0.076 \\
\hline & \pm 108.33 & \pm 88.21 & \\
\hline \multirow[t]{2}{*}{ Urine output $(\mathrm{mL})$} & 357.90 & 339.35 & 0.133 \\
\hline & \pm 56.48 & \pm 43.76 & \\
\hline Dexmedetomidine $\left(\mu \mathrm{kg}^{-1} \mathrm{~h}^{-1}\right)$ & $0.43 \pm 0.12$ & $0.32 \pm 0.10 * *$ & 0.001 \\
\hline Remifentanil $\left(\mu \mathrm{g} \cdot \mathrm{kg}^{-1} \cdot \mathrm{min}^{-1}\right)$ & $0.18 \pm 0.05$ & $0.14 \pm 0.04 * *$ & 0.001 \\
\hline Sevoflurane (\%) & $2.39 \pm 1.28$ & $1.78 \pm 1.01 *$ & 0.032 \\
\hline $\begin{array}{l}\text { Number of using vasoactive } \\
\text { agent } n(\%)\end{array}$ & 27 (77.14\%) & 18 (52.94\%)* & 0.045 \\
\hline Cisatracurium dosage $\left(\mathrm{mg} \mathrm{kg}^{-1}\right)$ & $0.25 \pm 0.04$ & $0.24 \pm 0.02$ & 0.196 \\
\hline
\end{tabular}

Notes: Variables presented as mean \pm SD or number of patients $n(\%)$. $* P<0.05$ vs Group C; **p $<0.01$ vs Group C.

Abbreviations: BMI, body mass index; ASA, American Society of Anesthesiology; FEVI/FVC, forced vital capacity rate of one second/forced vital capacity; CCRT, concurrent chemoradiation therapy; PACU, post-anesthesia care unit.

( $42.86 \%$ vs $17.65 \%, P=0.023$; Table 6). Pneumonia was more frequent in the $\mathrm{C}$ group; however, the difference was not significant $(20.00 \%$ vs $5.88 \%, P=0.151$; Table 6$)$. There were no cardiovascular events such as myocardial infarction, cerebrovascular accident, deep venous thrombosis, or pulmonary embolism in either group ( $P>0.05$, Table 6).

The prevalence rates of chronic pain 3 and 6 months after surgery were lower in the $\mathrm{P}$ group, but the differences were not significant at either time point $(P>0.05$, Figure 6$)$.

\section{Discussion}

In this study, we demonstrated that PVB combined with parecoxib as multimodal postoperative analgesia exerted an opioid-sparing effect and significantly reduced early postoperative pain level. It was associated with a lower incidence of hemodynamic instability, reduced sufentanil, and rescue ketorolac consumption, and a suppressed surgery-related stress response. The rates of chronic pain 3 and 6 months after surgery and the complication rate (except urinary retention) were not significantly different between the two groups.

Previous studies have reported that patients who undergo VATS suffer from moderate acute and chronic postoperative pain related to the incision, pleural inflammation, pulmonary parenchymal damage, and chest tube placement. $^{2,25}$ Poorly controlled pain may be associated with increased rates of hypoxia, dys-expectoration, and pneumonia. This underscores the need for multimodal analgesic strategies to decrease the incidence of complications after VATS. ${ }^{26,27}$

PVB produces an analgesic effect by blocking ipsilaterally without affecting the contralateral somatosensory and sympathetic nerves. Considering the time, risk, and complexity for regional techniques, it was used only for up to $50 \%$ of VATS in the UK from 2009 to $2010 .{ }^{12}$ Thoracic PVB efficacy depends on both the injection and local anesthetic agent. ${ }^{28} \mathrm{~A}$ previous study reported that the failure rate for PVB without ultrasound guidance was $>10 \%$, and risk of accidental pleural puncture was $1.1 \% .{ }^{29-31} \mathrm{As}$ a result, we employed the ultrasound guidance method to improve the success rate and reduce complications.

Considering the reported cardiotoxicity of bupivacaine, we selected ropivacaine as the first choice for PVB. $^{32}$ According to a previous study, an intact pleura is essential for effective thoracic PVB. ${ }^{33}$ In contrast to continuous $\mathrm{PVB}$, one single administration has no technical challenges, but the duration of effect may only be $\sim 6 \mathrm{~h}^{34}$ To extend the benefit from PVB, we administered postoperative PCIA with sufentanil. One group reported that dexmedetomidine can prolong the duration of nerve block and intravertebral anesthesia when combined with local anesthetic without sedation. ${ }^{35} \mathrm{We}$, therefore, injected $5 \mathrm{~mL}$ of $0.5 \%$ ropivacaine containing $0.3 \mu \mathrm{g} / \mathrm{kg}$ dexmedetomidine each from T4 to T8 in the PVB, which is considered safe according to a previous report. ${ }^{36}$ Compared to the $\mathrm{C}$ group, patients in $\mathrm{P}$ group had lower VAS scores both at rest and with coughing during the first $24 \mathrm{~h}$ after surgery, indicating that PVB combined with parecoxib could provide effective postoperative pain control. Notably, both the time to first dose rescue ketorolac and total consumption of ketorolac were significantly lower in 


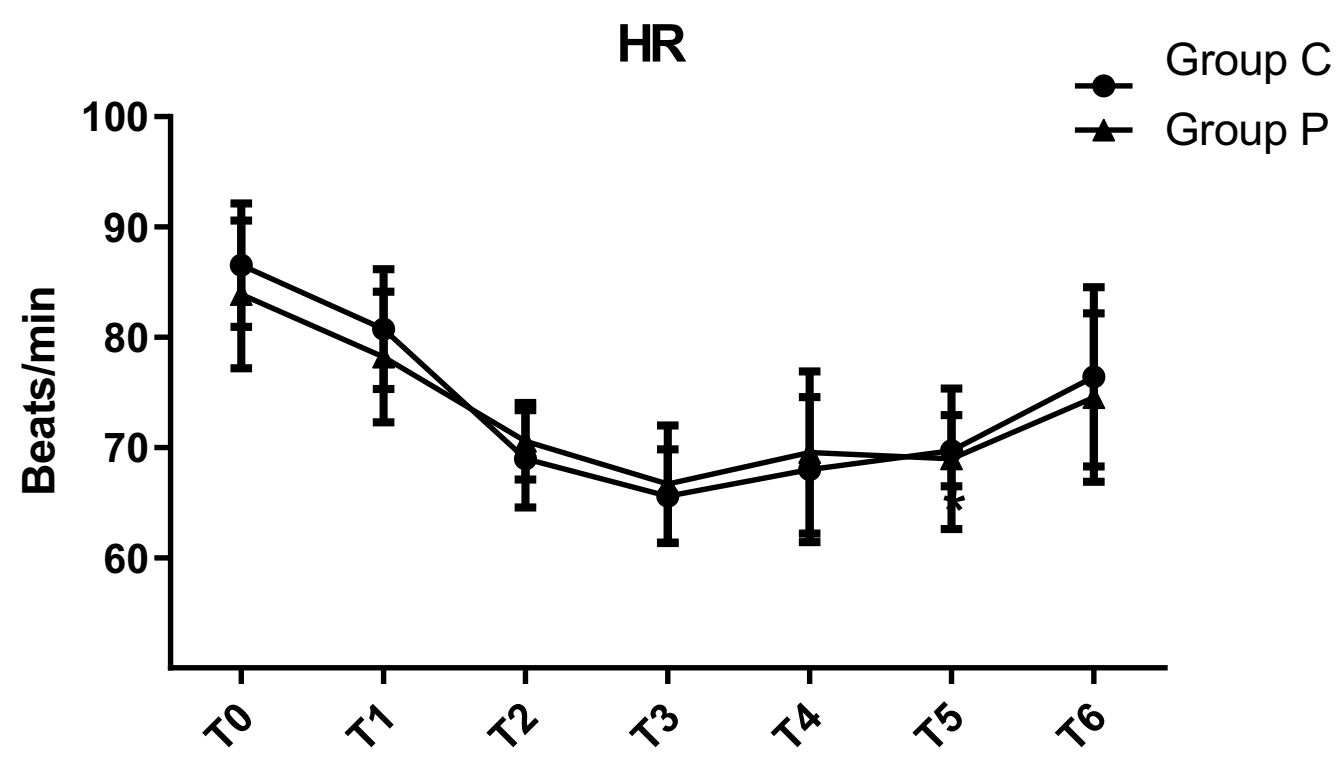

Time

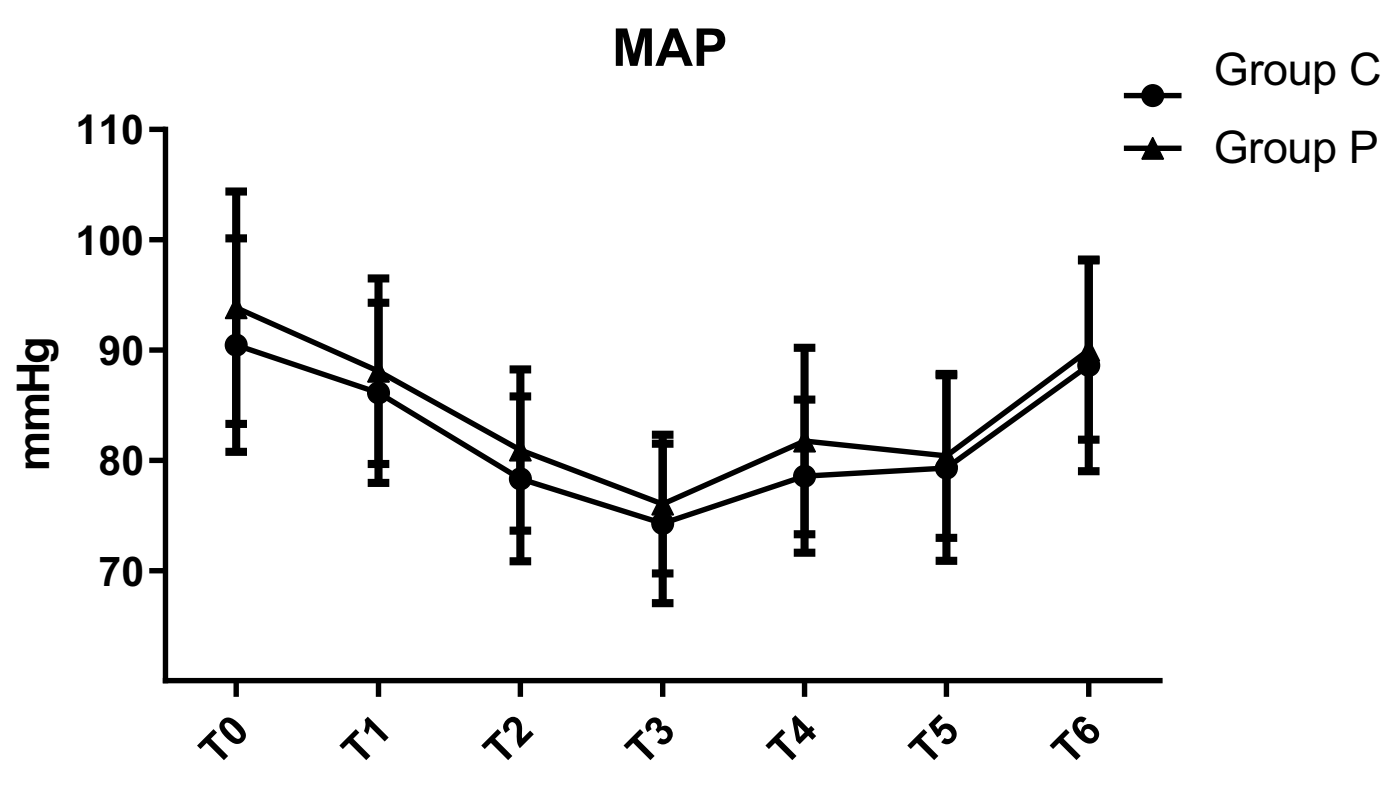

Time

Figure 2 Intraoperative hemodynamic changes.

C group, although the requirement for rescue analgesic during $48 \mathrm{~h}$ after surgery was similar between groups. We did not place the catheter in the paravertebral space for both the technical reasons and the risk of catheter-related complications. $^{37}$

Consistent with the results of the previous study, patients in the P group tended to have better pain control. Different kinds and concentrations of drugs, the injection numbers for
PVB, and the detailed methods and procedures of VATS may explain this significant heterogeneity. ${ }^{38}$ Although the total amount of ropivacaine was high, there were no clinical symptoms of toxicity. One explanation for the shorter duration of PVB in this study is that all anesthesiologists were familiar with the procedure in both hospitals. A previous study reported that combined use of different regional techniques may further reduce the risk of failed analgesia; 


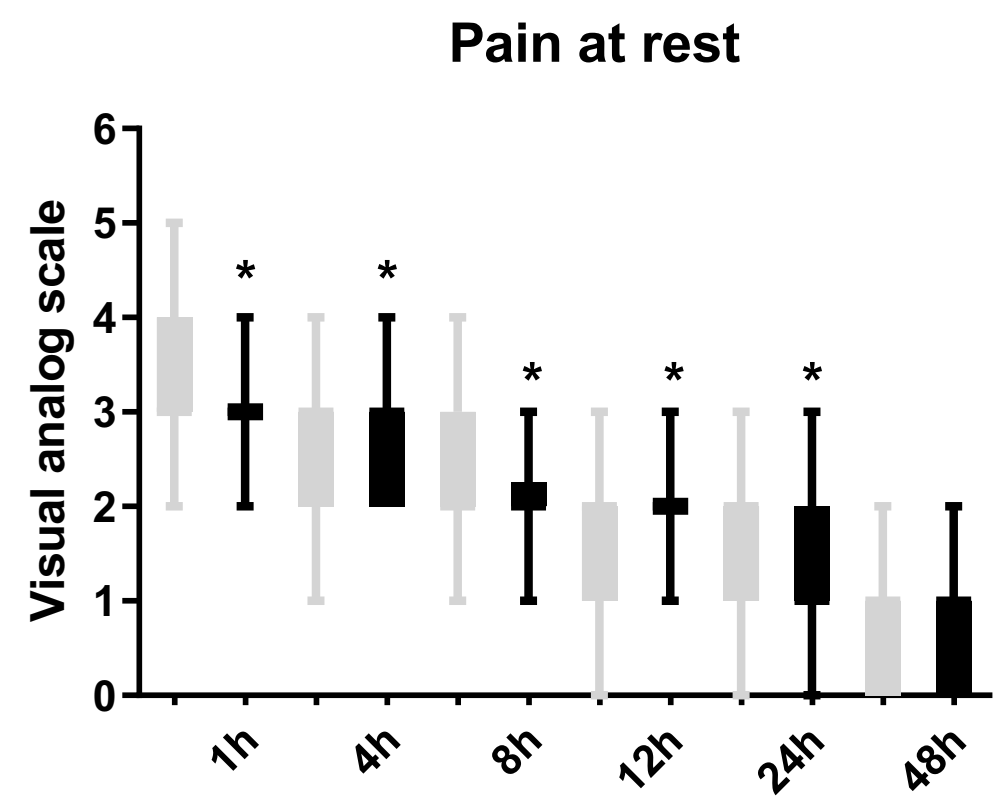

Time

\section{Pain with coughing}

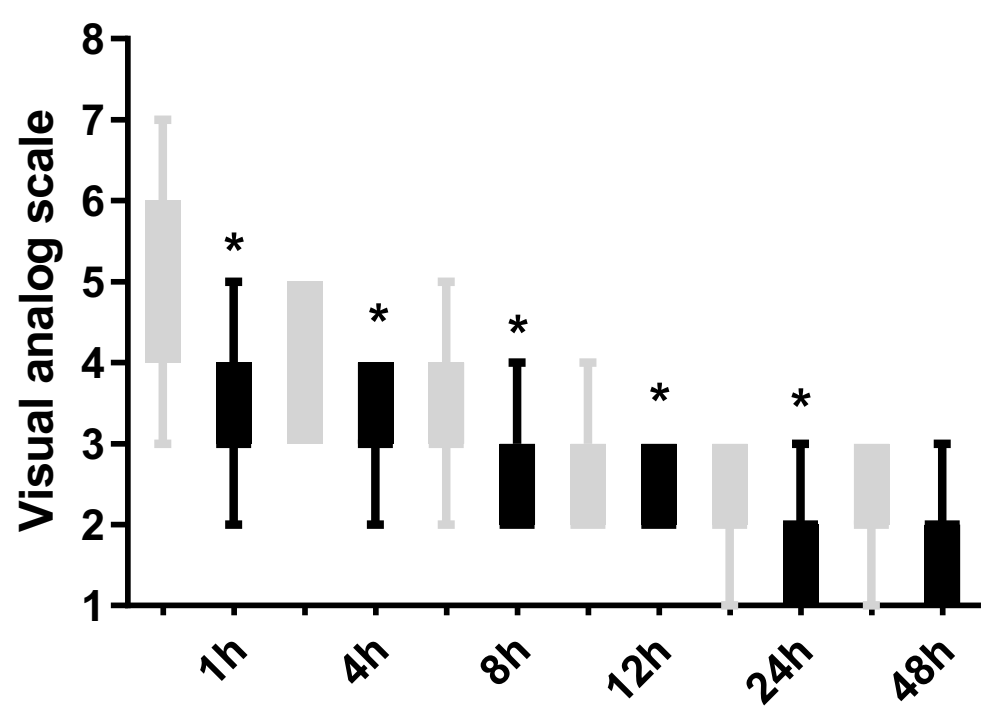

\section{Time}

Figure 3 Postoperative pain intensity (at rest and with coughing) between the two groups expressed as VAS scores (0-10). $* P<0.05$ vs group $C$.

however, the chance of local anesthesia toxicity would increase. ${ }^{4}$ Cheema et al found that sensory level block reached 2.2 segments above and 1.4 segments below the level of injection and suggested that multiple-level injections with smaller boluses would be better than a large-volume single injection. ${ }^{39}$ As a result, we employed a multiple- injection thoracic PVB (T4-T8 intercostal space) approach before surgery. In addition, the number of patients with chest tube removed, length of stay, out of bed and walking with support in $48 \mathrm{~h}$ after surgery hospital stay is remarkably decreased in the $\mathrm{P}$ group, which is very important for the enhanced recovery after VATS. 


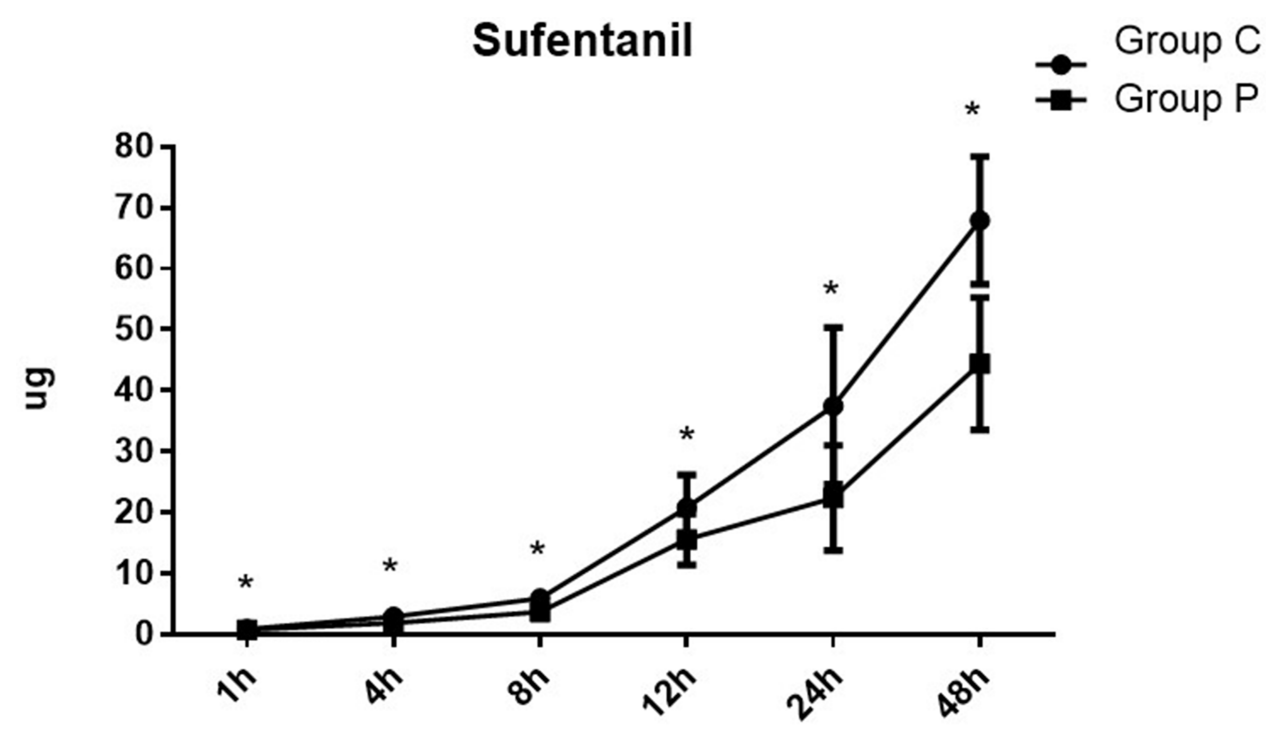

Time

Figure 4 Postoperative sufentanil consumption in both groups. ${ }^{*} P<0.05$ vs group $C$.

We also tested the hypothesis that an analgesic strategy is more effective if given before the noxious stimulus. Previous studies have confirmed that preemptive analgesia could decrease rates of hyperalgesia and allodynia by

Table 2 The Rescue Analgesia During 48 h After Surgery in the Two Groups

\begin{tabular}{|l|l|l|l|}
\hline & $\begin{array}{l}\text { Group C } \\
(\mathbf{n = 3 5 )}\end{array}$ & $\begin{array}{l}\text { Group P } \\
(\mathbf{n = 3 4 )}\end{array}$ & P-values \\
\hline $\begin{array}{l}\text { Numbers of rescue } \\
\text { analgesia, n (\%) }\end{array}$ & $12(34.29 \%)$ & $6(17.67 \%)$ & 0.171 \\
\hline $\begin{array}{l}\text { The time to first dose of } \\
\text { rescue ketorolac (min) }\end{array}$ & $\begin{array}{l}45.36 \\
(25.98-128.38)\end{array}$ & $\begin{array}{l}76.44 \\
(35.83-218.35) *\end{array}$ & 0.034 \\
\hline $\begin{array}{l}\text { Total dose of rescue } \\
\text { ketorolac (mg) }\end{array}$ & $18.25 \pm 6.54$ & $12.10 \pm 4.56^{* *}$ & 0.001 \\
\hline
\end{tabular}

Notes: Variables presented as number of patients $\mathrm{n}(\%)$ or median (interquartile range). $* P<0.05$ vs Group $C ; * * P<0.01$ vs Group $C$.

Table 3 LOS During 48 h After Surgery in the Two Groups

\begin{tabular}{|l|l|l|l|l|}
\hline & & Group C (n=35) & Group P (n=34) & P-values \\
\hline LOS & Ih & I (I-2) & I (0-2) & 0.063 \\
& $4 \mathrm{~h}$ & $\mathrm{I}(0-2)$ & $\mathrm{I}(0-\mathrm{I})$ & $0.3 \mathrm{I}$ \\
& $8 \mathrm{~h}$ & $0(0-\mathrm{I})$ & $0(0-\mathrm{I})$ & 0.547 \\
& $\mathrm{I} 2 \mathrm{~h}$ & $0(0-0)$ & $0(0-0)$ & 1.000 \\
& $24 \mathrm{~h}$ & $0(0-0)$ & $0(0-0)$ & 1.000 \\
& $48 \mathrm{~h}$ & $0(0-0)$ & $0(0-0)$ & 1.000 \\
\hline
\end{tabular}

Note: Variables presented as median (interquartile range). Abbreviation: LOS, level of sedation. normalizing altered central sensory processing. ${ }^{40}$ Parecoxib is a selective COX-2 inhibitor that is less likely to cause gastrointestinal bleeding and acute kidney injury. ${ }^{41}$ It can reduce the production and synthesis of

Table 4 Comparison of Postoperative Variables in the Two Groups

\begin{tabular}{|l|l|l|l|}
\hline Variable & $\begin{array}{l}\text { Group C } \\
(\mathbf{n = 3 5 )}\end{array}$ & $\begin{array}{l}\text { Group P } \\
(\mathbf{n = 3 4 )}\end{array}$ & P-values \\
\hline Recovery time (min) & $16.24 \pm 4.15$ & $12.48 \pm 3.29 * *$ & 0.001 \\
$\begin{array}{l}\text { Patient satisfaction score } \\
\text { Surgeon satisfaction } \\
\text { score }\end{array}$ & $4.00(3.25-5.00)$ & $4.25(3.75-5.00)$ & 0.065 \\
\hline
\end{tabular}

Notes: Variables presented as mean $\pm \mathrm{SD}$ or median (interquartile range). $* * P<0.01$ vs Group C.

Table 5 Postoperative Data

\begin{tabular}{|l|l|l|l|}
\hline & $\begin{array}{l}\text { Group C } \\
(\mathbf{n = 3 5 )}\end{array}$ & $\begin{array}{l}\text { Group P } \\
(\mathbf{n}=\mathbf{3 4})\end{array}$ & P-values \\
\hline Chest tube removed (d) & $2.57 \pm 1.23$ & $1.91 \pm 0.56 * *$ & 0.006 \\
Out of bed in 48 h, $\mathrm{n}(\%)$ & $25(71.43 \%)$ & $32(94.12 \%) *$ & 0.013 \\
Walking with support in $48 \mathrm{~h}$, & $19(54.29 \%)$ & $25(73.53 \%)$ & 0.096 \\
$\mathrm{n}(\%)$ & & & \\
Length of stay (d) & $6.59 \pm 2.53$ & $6.51 \pm 2.29$ & 0.890 \\
FEVI/FVC in 24 h (\%) & $78.26 \pm 5.28$ & $82.58 \pm 6.87 *$ & 0.037 \\
FEVI/FVC in 72 h (\%) & $82.61 \pm 7.21$ & $86.98 \pm 4.26 * *$ & 0.002 \\
\hline
\end{tabular}

Notes: Variables presented as mean \pm SD or number of patients $n(\%)$. $* P<0.05$ vs Group C; **P $<0.01$ vs Group C.

Abbreviation: $\mathrm{FEVI} / \mathrm{FVC}$, forced vital capacity rate of one second/forced vital capacity. 

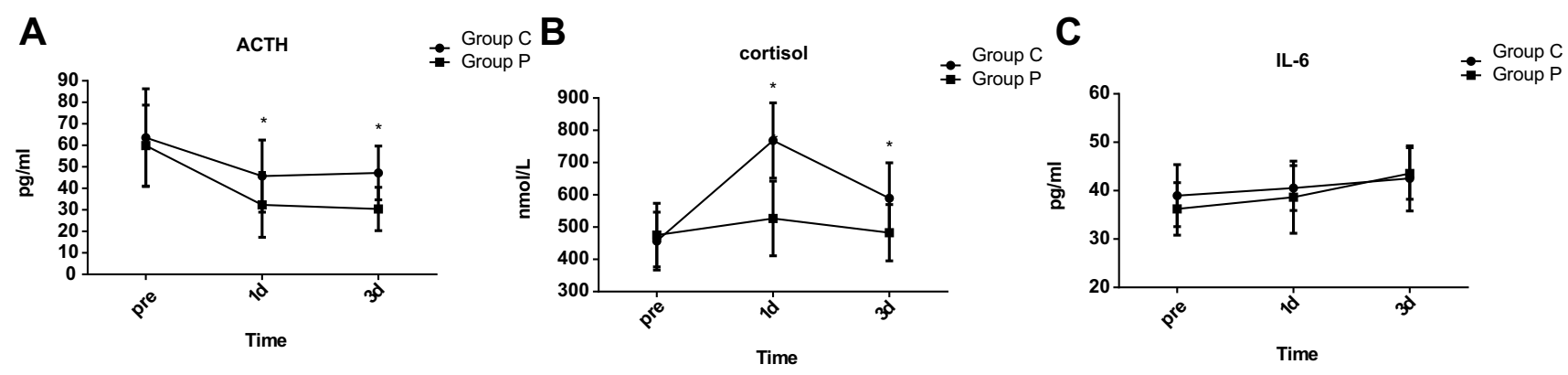

Figure 5 (A-C) The concentrations of ACTH, cortisol, and IL-6 in both groups. $* P<0.05$ vs group $C$.

spinal prostaglandin, which may be involved in the pathological processes of inflammation, pain, and apoptosis. The first dosage of parecoxib in this study was given 0.5 $\mathrm{h}$ before surgery to maximize its preemptive analgesia effect according to a previous study. ${ }^{42}$ We did not observe any complications related to parecoxib in the $\mathrm{P}$ group, indicating that it is safe for patients undergoing VATS. The incidence of chronic postthoracotomy pain syndrome (PTPS) was not found to be different between VATS and thoracotomy. ${ }^{43}$ Although a previous study concluded that the risk factors of ipsilateral shoulder pain (ISP) were thoracotomy and length of surgery $>120 \mathrm{~min}$, patients who underwent VATS also experienced varying degrees of ISP. ${ }^{44}$ We interviewed the patients by telephone 3 and 6 months after surgery and found that those given PVB combined with parecoxib had a lower incidence of PTPS, but the difference was not significant. Future investigations should compare the efficacies of different doses of parecoxib during VATS.

Inflammatory markers were measured at three time points with apparent differences between the two groups. Our findings suggest that the patterns of cortisol and ACTH levels may be partly due to analgesia effectiveness.

Table 6 Postoperative Adverse Effects in the Two Groups

\begin{tabular}{|l|l|l|l|}
\hline & $\begin{array}{l}\text { Group C } \\
\text { (n=35) }\end{array}$ & $\begin{array}{l}\text { Group P } \\
\text { (n=34) }\end{array}$ & P-values \\
\hline Nausea & $19(54.29 \%)$ & $12(35.29 \%)$ & 0.113 \\
Urinary retention & $15(42.86 \%)$ & $6(17.65 \%)$ & $0.023^{*}$ \\
Itching & $4(11.43 \%)$ & $5(14.71 \%)$ & 0.734 \\
Hypotension & $12(34.29 \%)$ & $8(23.53 \%)$ & 0.325 \\
Pneumonia & $7(20.00 \%)$ & $2(5.88 \%)$ & 0.151 \\
Cardiovascular & 0 & 0 & 1.000 \\
events & & & \\
\hline
\end{tabular}

Notes: Variables presented as number of patients $n(\%) . * P<0.05$ vs Group $C$.
A previous study reported that the beneficial effects of ropivacaine may be due to both sodium channel blockade and anti-inflammatory actions. ${ }^{45}$ There were no differences in IL-6 concentrations between the two groups, which may be due to the slower IL-6 response following inflammation. ${ }^{46}$

Limitations of the study: Firstly, a previous study showed that sevoflurane could directly inhibit hypoxic pulmonary vasoconstriction, which may affect our results. ${ }^{47}$ Secondly, some postoperative discomfort comes from chest tuberelated pain that is not sufficiently blocked by PVB. This may be due to the unblocked nociceptive signals from the long thoracic nerve (LTN), phrenic nerve, thoracodorsal nerve, and vagus nerve. One group reported that serratus anterior plane block could provide optimal analgesia for chest tube-related pain. ${ }^{48}$ Thirdly, we did not record the amount of ropivacaine although no $\mathrm{P}$ group patients suffered from local anesthetic toxicity-related complications. Fourthly, we used $0.3 \mu \mathrm{g} / \mathrm{kg}$ dexmedetomidine in addition to ropivacaine based on previous studies, a dose-response study was not performed to confirm the optimum dexmedetomidine dose. Finally, the relatively small sample size and recruitment of healthy patients with ASA I and II limited the

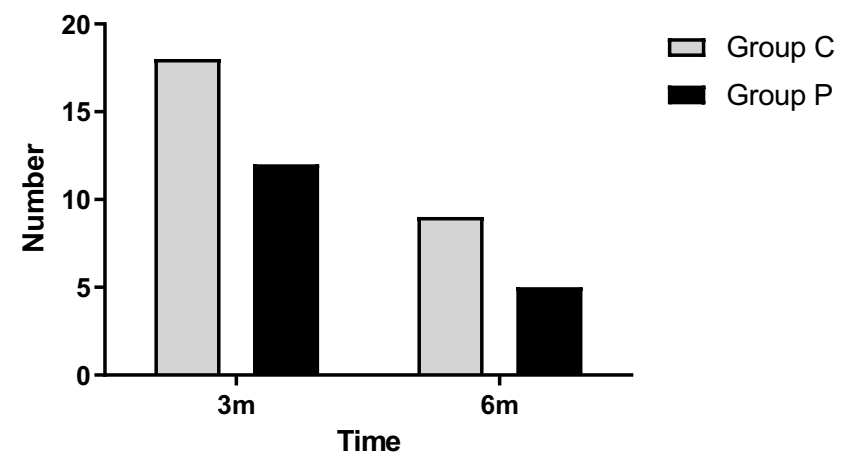

Figure 6 Patients with chronic pain 3 and 6 months after surgery in each group. 
generalizability of our findings. More patients with ASA >II should be included in future studies.

In summary, preemptive ultrasound-guided PVB combined with parecoxib could reduce sufentanil consumption and pain severity in the early postoperative period. It was associated with a lower incidence of hemodynamic instability, less sufentanil and rescue ketorolac consumption, and a decreased surgery-related stress response. The incidence rates of chronic pain 3 and 6 months after surgery and complications (except urinary retention) were similar between the two groups. More randomized controlled trials are required to evaluate the optimal PVB with parecoxib protocols for different populations of patients undergoing VATS.

\section{Ethical Approval}

All procedures performed in studies involving human participants were in accordance with the ethical standards of the institutional and/or national research committee and with the 1964 Helsinki Declaration and its later amendments or comparable ethical standards.

\section{Data Sharing Statement}

The authors intend to share participants' data collected during the trial. This includes study protocol, statistical analysis plan, informed consent forms, and clinical study report. It will be available based on the request of investigators whose proposed use of the data has been approved by an independent review committee by sending an email to the corresponding author. Data are available immediately after publication and with no end date.

\section{Author Contributions}

All authors contributed to data analysis, drafting or revising the article, gave final approval of the version to be published, and agree to be accountable for all aspects of the work.

\section{Funding}

This work was supported by the Natural Science Foundation of Shandong Province (ZR2016HB28) and Beijing Medical Award Foundation (YXJL-2019-01630025).

\section{Disclosure}

The authors declare no competing interests.

\section{References}

1. Detillon DDEMA, Aarts MJ, De Jaeger K, et al. Video-assisted thoracic lobectomy versus stereotactic body radiotherapy for stage I nonsmall cell lung cancer in elderly patients: a propensity matched comparative analysis. Eur Respir J. 2019;53(6):1801561.

2. Bendixen M, Jørgensen OD, Kronborg C, et al. Postoperative pain and quality of life after lobectomy via video-assisted thoracoscopic surgery or anterolateral thoracotomy for early stage lung cancer: a randomised controlled trial. Lancet Oncol. 2016;17(6):836-844.

3. Strassels SA, Chen C, Carr DB. Postoperative analgesia: economics, resource use, and patient satisfaction in an urban teaching hospital. Anesth Analg. 2002;94(1):130-137.

4. Umari M, Carpanese V, Moro V, et al. Postoperative analgesia after pulmonary resection with a focus on video-assisted thoracoscopic surgery. Eur J Cardiothorac Surg. 2018;53(5):932-938.

5. Xu J, Yang X, Hu X, et al. Multilevel thoracic paravertebral block using ropivacaine with/without dexmedetomidine in video-assisted thoracoscopic surgery. J Cardiothorac Vasc Anesth. 2018;32(1):318-324.

6. You HJ, Lei J, Xiao Y, et al. Pre-emptive analgesia and its supraspinal mechanisms: enhanced descending inhibition and decreased descending facilitation by dexmedetomidine. J Physiol. 2016;594(7):1875-1890.

7. Van Backer JT, Jordan MR, Leahy DT, et al. Preemptive analgesia decreases pain following anorectal surgery: a prospective, randomized, double-blinded, placebo-controlled trial. Dis Colon Rectum. 2018;61(7):824-829.

8. Joshi GP, Bonnet F, Shah R, et al. A systematic review of randomized trials evaluating regional techniques for postthoracotomy analgesia. Anesth Analg. 2008;107(3):1026-1040.

9. Raveglia F, Rizzi A, Leporati A, et al. Analgesia in patients undergoing thoracotomy: epidural versus paravertebral technique. A randomized, double-blind, prospective study. $J$ Thorac Cardiovasc Surg. 2014;147(1):469-473.

10. Harky A, Clarke CG, Kar A, et al. Epidural analgesia versus paravertebral block in video-assisted thoracoscopic surgery. Interact Cardiovasc Thorac Surg. 2019;28(3):404-406.

11. Davies RG, Myles PS, Graham JM. A comparison of the analgesic efficacy and side-effects of paravertebral vs epidural blockade for thoracotomy-a systematic review and meta-analysis of randomized trials. Br J Anaesth. 2006;96(4):418-426.

12. Dualé C, Gayraud G, Taheri H, et al. A French nationwide survey on anesthesiologist-perceived barriers to the use of epidural and paravertebral block in thoracic surgery. $J$ Cardiothorac Vasc Anesth. 2015;29(4):942-949.

13. Chen N, Qiao Q, Chen R, et al. The effect of ultrasound-guided intercostals nerve block, single-injection erector spinae plane block and multiple-injection paravertebral block on postoperative analgesia in Thoracoscopic surgery: a randomized, double-blinded, clinical trial. J Clin Anesth. 2020;59:106-111.

14. Pawa A, Wight J, Onwochei DN, et al. Combined thoracic paravertebral and pectoral nerve blocks for breast surgery under sedation: a prospective observational case series. Anaesthesia. 2018;73(4):438-443.

15. Sessler DI, Pei L, Huang Y, et al. Recurrence of breast cancer after regional or general anaesthesia: a randomised controlled trial. Lancet. 2019;394(10211):1807-1815.

16. Bian YY, Wang LC, Qian WW, et al. Role of parecoxib sodium in the multimodal analgesia after total knee arthroplasty: a randomized double-blinded controlled trial. Orthop Surg. 2018;10(4):321-327.

17. Nussmeier NA, Whelton AA, Brown MT, et al. Safety and efficacy of the cyclooxygenase-2 inhibitors parecoxib and valdecoxib after noncardiac surgery. Anesthesiology. 2006;104(3):518-526.

18. Ren C, Zhang X, Liu Z, et al. Effect of intraoperative and postoperative infusion of dexmedetomidine on the quality of postoperative analgesia in highly nicotine-dependent patients after thoracic surgery: a CONSORT-prospective, randomized, controlled trial. Medicine (Baltimore). 2015;94(32):e1329. 
19. Bunchungmongkol N, Pipanmekaporn T, Paiboonworachat S, et al. Incidence and risk factors associated with ipsilateral shoulder pain after thoracic surgery. J Cardiothorac Vasc Anesth. 2014;28 (4):979-982.

20. Borro JM, Gonzalez D, Paradela M, et al. The two-incision approach for video-assisted thoracoscopic lobectomy: an initial experience. Eur J Cardiothorac Surg. 2011;39(1):120-126.

21. Visoiu M, Scholz S. Thoracoscopic and ultrasound guidance for optimization of medication spread during thoracic paravertebral nerve blockade. Anesthesiology. 2018;129(6):1167-1168.

22. Tamura T, Yokota S, Ito S, et al. Local anesthetic spread into the paravertebral space with two types of quadratus lumborumblocks: a crossover volunteer study. J Anesth. 2019;33(1):26-32.

23. Wu Z, Fang S, Wang Q, et al. Patient-controlled paravertebral block for video-assisted thoracic surgery: a randomized trial. Ann Thorac Surg. 2018;106(3):888-894.

24. Hill SE, Keller RA, Stafford-Smith M, et al. Efficacy of single-dose, multilevel paravertebral nerve blockade for analgesia after thoracoscopic procedures. Anesthesiology. 2006;104(5):1047-1053.

25. Liu CY, Cheng CT, Wang BY, et al. Number of Retrieved Lymph Nodes And Postoperative Pain In Single-Incision And Multiple-Incision Thoracoscopic Surgery. Ann Surg. 2017;265(6): E76-E77.

26. Piccioni F, Segat M, Falini S, et al. Enhanced recovery pathways in thoracic surgery from Italian VATS Group: perioperative analgesia protocols. J Thorac Dis. 2018;10(Suppl 4):S555-S563.

27. van der Ploeg APT, Ayez N, Akkersdijk GP, et al. Postoperative pain after lobectomy: robot-assisted, video-assisted and open thoracic surgery. J Robot Surg. 2019. doi:10.1007/s11701-019-00953-y

28. Fibla JJ, Molins L, Mier JM, et al. The efficacy of paravertebral block using a catheter technique for postoperative analgesia in thoracoscopic surgery: a randomized trial. Eur J Cardiothorac Surg. 2011;40(4):907-911.

29. Krediet AC, Moayeri N, van Geffen GJ, et al. Different Approaches to Ultrasound-guided Thoracic Paravertebral Block: an Illustrated Review. Anesthesiology. 2015;123(2):459-474.

30. Uppal V, Sondekoppam RV, Sodhi P, et al. Single-injection versus multiple-injection technique of ultrasound-guided paravertebral blocks: a randomized controlled study comparing dermatomal spread. Reg Anesth Pain Med. 2017;42(5):575-581.

31. Saito T, Den S, Cheema SP, et al. A single-injection, multi-segmental paravertebral block-extension of somatosensory and sympathetic block in volunteers. Acta Anaesthesiol Scand. 2001;45(1):30-33.

32. Dureau P, Charbit B, Nicolas N, et al. Effect of intralipid ${ }^{\circledR}$ on the dose of ropivacaine or levobupivacaine tolerated by volunteers: a clinical and pharmacokinetic study. Anesthesiology. 2016;125 (3):474-483

33. Komatsu T, Sowa T, Kino A, et al. The importance of pleural integrity for effective and safe thoracic paravertebral block: a retrospective comparative study on postoperative pain control by paravertebral block. Interact Cardiovasc Thorac Surg. 2015;20 (3):296-299.
34. Fibla JJ, Molins L, Mier JM, et al. A randomized prospective study of analgesic quality after thoracotomy: paravertebral block with bolus Versus continuous infusion with an elastomeric pump. Eur J Cardiothorac Surg. 2015;47(4):631-635.

35. Abdallah FW, Brull R. Facilitatory effects of perineural dexmedetomidine on neuraxial and peripheral nerve block: a systematic review and meta-analysis. Br J Anaesth. 2013;110(6):915-925.

36. Zhang W, Li C. EC50 of epidural ropivacaine combined with dexmedetomidine for labor analgesia. Clin J Pain. 2018;34(10):950-953.

37. Womack J, Pearson JD, Walker IA. Safety, complications and clinical outcome after ultrasound-guided paravertebral catheter insertion for rib fracture analgesia: a single-centre retrospective observational study. Anaesthesia. 2019;74(5):594-601.

38. Hutchins J, Sanchez J, Andrade R, et al. Ultrasound-guided paravertebral catheter versus intercostal blocks for postoperative pain control in video-assisted thoracoscopic surgery: a prospective randomized trial. J Cardiothorac Vasc Anesth. 2017;31(2):458-463.

39. Cheema SP, Ilsley D, Richardson J, et al. A thermographic study of paravertebral analgesia. Anaesthesia. 1995;50(2):118-121.

40. Fiorelli A, Vicidomini G, Laperuta P, et al. Pre-emptive local analgesia in video-assisted thoracic surgery sympathectomy. Eur J Cardiothorac Surg. 2010;37(3):588-593.

41. Tiippana E, Nelskylä K, Nilsson E, et al. Managing post-thoracotomy pain: epidural or systemic analgesia and extended care A randomized study with an "as usual" control group. Scand J Pain. 2014;5(4):240-247.

42. Xiao K, Yu L, Xiao W, et al. Pain management using perioperative administration of parecoxib for total hip arthroplasty: a randomized, double-blind, placebo-controlled trial. Pain Physician. 2019;22 (6):575-582.

43. Shanthanna H, Aboutouk D, Poon E, et al. A retrospective study of open thoracotomies versus thoracoscopic surgeries for persistent postthoracotomy pain. J Clin Anesth. 2016;35:215-220.

44. Rodríguez-Torres J, Lucena-Aguilera MDM, Cabrera-Martos I, et al. Musculoskeletal signs associated with shoulder pain in patients undergoing video-assisted thoracoscopic surgery. Pain Med. 2018;20:1997-2003.

45. YaDeau JT, Gordon MA, Goytizolo EA, et al. Buprenorphine, clonidine, dexamethasone, and ropivacaine for interscalene nerve blockade: a prospective, randomized, blinded, ropivacaine dose-response study. Pain Med. 2016;17(5):940-960.

46. Menna C, De Falco E, Teodonio L, et al. Surgical wound-site inflammation: video-assisted thoracic surgery versus thoracotomy. Interact Cardiovasc Thorac Surg. 2019;28(2):240-246.

47. Matsuse S, Hara Y, Ohkura T. The possible influence of pulmonary arterio-venous shunt and hypoxic pulmonary vasoconstriction on arterial sevoflurane concentration during one-lung ventilation. Anesth Analg. 2011;112(2):345-348.

48. Chen G, Li Y, Zhang Y, et al. Effects of serratus anterior plane block for postoperative analgesia after thoracoscopic surgery compared with local anesthetic infiltration: a randomized clinical trial. J Pain Res. 2019;12:2411-2417.
Journal of Pain Research

\section{Publish your work in this journal}

The Journal of Pain Research is an international, peer reviewed, open access, online journal that welcomes laboratory and clinical findings in the fields of pain research and the prevention and management of pain. Original research, reviews, symposium reports, hypothesis formation and commentaries are all considered for publication. The manuscript management system is completely online and includes a very quick and fair peer-review system, which is all easy to use. Visit http:// www.dovepress.com/testimonials.php to read real quotes from published authors. 